\title{
The Significance of Love and Selflessness in Iris Murdoch's Moral Philosophy
}

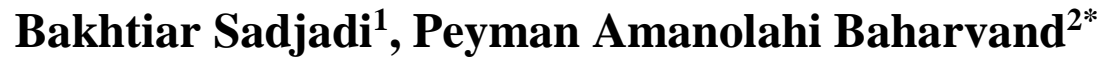 \\ Faculty of Language and Literature, University of Kurdistan, Sanandaj, Iran ${ }^{1}$; Department \\ of English Language, School of Medicine, Lorestan University of Medical Sciences, \\ Khorramabad, Iran ${ }^{2}$ \\ *Corresponding author: amanolahi1984@yahoo.com
}

\begin{abstract}
As a distinguished philosopher and novelist in the second half of the twentieth century, Iris Murdoch addressed the significance of ethics in her framework of thought. . Murdoch's moral philosophy was widely acknowledged as a challenge to the prevailing ethical traditions which, she asserted, had failed to present an accurate picture of morality. As a philosopher and literary figure, Murdoch maintained that not only moral philosophy but also literature should depict perceptible pictures of man's morality. The purpose of this paper is to closely explore Murdoch's perspective towards the weight of love in moral philosophy. Since she was concerned with ethical issues and man's confrontation with ethical questions in a world in which religious values and beliefs had been shattered, Murdoch deployed literature to convey the concepts she advocated in her moral philosophy. She contended that literature was capable of sustaining and improving man's morality. Murdoch was a prolific novelist and playwright authoring 26 novels and 6 plays in which she developed and reflected her philosophical arguments through the portrayal of her intended ethical behavior. This tendency is mostly highlighted in The Flight from the Enchanter (1956), and The Severed Head (1961) in which Murdoch resorts to Plato's theory of Forms and his idea of the Good to combat the conventional moral philosophy of the twentieth century. Based on the findings of this article, Murdoch intends to depict the significance of freedom and love as the prerequisites of morality in any philosophical system.
\end{abstract}

Keywords: morality, love, the Good, truth, philosophy

\section{Introduction}

Dame Jean Iris Murdoch (1919-1999) was a distinguished Irish philosopher and a prolific novelist and playwright whose literary works, particularly her psychological novels, contain philosophical arguments. Murdoch referred to literature as a principal component of culture that deserves reverence. "The most essential and fundamental aspect of culture is the study of literature, since this is an education in 
how to picture and understand human situations" (Murdoch, 1964: p.346). She maintained that literature could have an essential role in the formulation of ethical principles. Murdoch commenced her philosophical career with a critical study entitled Sartre, Romantic Rationalist (1953), and subsequently turned to novel as her favorite literary genre in the next year through the publication of Under the Net (1954) that was followed by The Flight from the Enchanter in 1956. She reached the apex of her career as a novelist after publishing The Bell in 1958 that contributed to her recognition throughout the world as a prominent novelist. She continued her career as a novelist with the publication of 26 novels in which a variety of subjects including good and evil, sexual affairs, ethics and the capabilities of the unconscious were examined.

Murdoch included, for instance, unconventional homosexual characters and a strong and devilish male enchanter who insidiously influences other characters in The Flight from the Enchanter. Murdoch's remarkable achievements as a novelist eclipsed her philosophical career in 1960s and 1970s. However, she expressed her philosophical theories through novels. "Murdoch called herself a moral psychologist and we also look at the ways in which the novels reveal her love of humanity and her just and tolerant presentation of human frailty, which is also a concern for representing human consciousness as accurately as possible in art" (Martin and Rowe, p.1). Murdoch's contribution to philosophy was primarily neglected by mainstream philosophers, for she was a nonconformist philosopher rigorously challenging the dominant philosophical arguments of the first half of the twentieth century including relativism, existentialism, behaviorism and prescriptivism. She is specifically known for her moral philosophy.

Murdoch was preoccupied with the perception of morality or what might be called the vision pertaining to the Platonic form of the Good. This conception of the Good, which is foregrounded in Murdoch's philosophical arguments, will be examined in this manuscript. Following the introduction section that presents a concise background of Murdoch's philosophical career, the significant studies already conducted on Murdoch's philosophical arguments will be briefly deal with in the review of literature. Subsequently, the code of ethics advocated by Murdoch will be outlined in the section title theoretical framework. The major research question to be answered in this section include whether Murdoch's moral philosophy is rooted in organized religions or it is originated in her own humanitarian perspectives. Finally, to indicate how Murdoch puts into practice her philosophical theories, The Flight from Enchanter (1956) and A Severed Head (1961), two novels written by Murdoch that are indeed narratives blended with philosophical ideas, will be briefly examined based on her arguments concerning ethics and moral philosophy. 


\section{Methodology}

The present research is categorized as a qualitative literature-based study for whose accomplishment the authors conducted library searches. Hence, a wide range of critical works were investigated to review the literature already written on Murdoch's philosophy. The reviewed articles and books provided insight into the subject of this study. Moreover, as a research project in humanities, this article required a particular theoretical framework rather than statistical analysis to examine the selected novels. Likewise, this article is a qualitative research that commences with a theoretical assumption and subsequently concentrates on the representations of the concept presented in the theory section.

\section{Literature Review}

Murdoch's moral philosophy has been examined in various scholarly articles, books and theses. To cite the major investigations already conducted on the issue, this section of the article reviews a number of them. Commending Murdoch's moral philosophy as an "ambitious attempt to develop a virtue ethics for the modern scene," Bridget Clarke (2013) defends her philosophy against the charge that it treats imagination as an enemy of both moral and philosophical development (p.387-388). Clarke maintains that this fallacious proposition is indeed based on the failure to recognize the distinction Murdoch makes between 'moral imagination' and 'fantasy'.

Clarke argues that according to Murdoch, unlike fantasy as a morally problematic concept, moral imagination could lead to virtue. On the other hand, Jessy E. G. Jordan (2013) examines "thick" ethical concepts in both philosophical arguments and literary works written by Murdoch. She notices that the investigation of thick ethical concepts that are central to Murdoch's thought is a neglected issue in Murdochian scholarship. Jordan maintains that although Murdock never used the expression thick ethical concept, this term refers to what this distinguished philosopher calls "secondary value words," and "normative-descriptive words" that are fundamental to Murdoch's moral philosophy.

Tony Milligan (2012) focuses on Murdoch's departure from analytic philosophy in an article titled "Iris Murdoch and the Borders of Analytic Philosophy". Millington remarks that Murdoch's philosophical arguments depart noticeably from conventional discursive norms including 'the norms concerning argument structure and the minimization of rhetoric' (p.164). Margaret Weldhen (2006) refers to Murdoch's description of our inner states of being in her article published in the 
Journal of Moral Education. According to Weldhen, Murdoch holds that philosophy should not be limited to rationality and theories of languages usage. It should rather include man's endeavor to express the inner moral experience.

Simon Haines's article, published in a book edited by Anne Rowe and Avril Horner (2010), is dedicated to the idea of "ethical turn and literary value" in Murdoch's philosophy. He holds that 1980s is characterized by the large-scale turn to ethics not only in literary studies but also in philosophy. Haines refers to Murdoch as "that rare creature" who was both a competent philosopher and a literary artist (p.88). He holds that Murdoch's understanding of "the Good" was an essential part of her moral philosophy. According to Haines, Murdoch used this term to refer to 'the privileged focus of attention or will' (ibid: p.88). Moreover, Haines focuses on Murdoch's understanding of literary study as a fundamental aspect of culture. Murdoch, he argues, refers to culture as "moral growth". Haines concludes that Murdoch holds literature in esteem.

\section{Theoretical Framework: Murdoch's Moral Philosophy}

Although she was a philosopher and an outstanding literary figure, Murdoch felt obliged to foster morality in the society that was dominated by cupidity and fantasy, the term she uses to refer to the spread of self-centeredness. "It is in the capacity to love, that is to see, that the liberation of the soul from fantasy consists. The freedom which is a proper human goal is the freedom from fantasy, that is the realism of compassion. What I have called fantasy, the proliferation of blinding self-centered aims and images" (Murdoch, 1970: p.65). Murdoch maintains that freedom from fantasy should be accompanied by the emancipation of the soul from ignorance and darkness. She utilizes Plato's theory of Forms to highlight man's virtual captivity.

Plato compares people who are unaware of the theory of Forms to prisoners chained in a cave unable even to turn their heads. They just observe the wall of the cave as they have their back at the fire blazing behind them. There are also some puppeteers behind the prisoners holding up puppets to cast shadow on the wall. Since the prisoners are ignorant of the existence of puppeteers, they do not see the puppets or the real objects moving behind them. Likewise, they just observe and hear the shadows and echoes cast by objects they cannot see. Consequently, the prisoners mistake the appearance for reality because they consider the shadows to be real objects.

When the prisoners discuss the things they observe, they are in fact referring to shadows. For instance, if a bunch of flowers is carried behind them, a prisoner who 
traces the flowers on the wall might think of the shadow as a real bunch of flowers. Hence, the prisoners watch a puppet show throughout their lives. Reality is, then, a puppet show created on the wall of the cave by puppeteers casting shadows of objects. The prisoners are ignorant of the real reference of the shadows they see as long as they have not turned their heads around to realize their misapprehensions. Human beings, Plato argues, have to turn their heads to see the origin of shadows and grasp the Forms through reliance on the power of mind.

The firelight is a metaphor for our understanding and the capability to realize the truth. Hence, a prisoner who intends to discover the truth has to break free of his chain and gaze at the fire, which represents enlightenment. The firelight might hurt the eyes and compel him to return and join the prisoners who are watching the shadows without any pain, but the result of submission is the protraction of ignorance. He has to adjust his eyes to the firelight, though it might be painful, to progress out of the cave into the sunlight. The released prisoner realizes the truth of everything when he looks at the sun. Inspired by Plato, Murdoch asserts that the ideal Form of the Good is indeed the light that indicates and reflects all things exactly as they are.

Those who remain in the cave are conformist subjects captivated in the cave of ignorance. They are even hostile to people who want to expand the horizon of their understanding. Murdoch invokes Plato's theory of the cave in The Sovereignty of Good (1970) to depict the factors that hinder our sympathetic concern for the sufferings or misfortunes of others. She intends to imply that it is only through the sunlight, or confronting the values, that we are able to watch what is really happening around us. Plato's cave could be compared to a dark room in which we would see only dark shapes and shadows. The act of switching on the light enables us to see what actually exists in the room. Similarly, moral values could induce drastic changes in our vision enabling us to find goodness in other people.

Murdock indicates the point by referring to a fictional mother who has developed hostile attitudes towards her daughter-in-law. The daughter-in-law is an obliging woman and at once an unpolished girl lacking refinement. The mother detests her daughter-in-law's accent or the way she dresses. She reckons that her son has married someone inferior to him. If the daughter-in-law gets out of sight due to either emigration or death, the mother might ponder on her ill-treatment of the daughterin-law. The misapprehension formed in the mother's mind is caused by jealousy that distorts the picture of her daughter-in-law as a silly vulgar woman who has married her son. Since she believes in the efficacy of literature, Murdoch formulates her philosophical theories in her novels. Likewise, she holds in one of her novels titled The Nice and The Good (1978) holds that "jealousy is a dreadful thing ... It is the 
most natural to us of the really wicked passions and it goes deep and envenoms the soul. It must be resisted with every honest cunning and with the deliberate thinking of generous thoughts" (p.175).

The mother represents the prisoner who has been chained in the cave. The emancipation of the imprisoned mother depends on her reevaluation of the bias that has misled her. This reevaluation should lead to self-criticism. She should cogitate on the object she gazes at, that is her daughter-in-law, to realize her error of judgement induced by jealousy and lack of love. According to Murdoch, "we can only learn to love by loving. Remember that all our failures are ultimately failures in love. Imperfect love must not be condemned and rejected but made perfect" (1978: p.192). Murdoch maintains that indifference, prejudice, snobbishness and lovelessness imprison us in dark caves. It is through the development of "virtuous consciousness" that the mother can find the goodness in her daughter-in-law. She notices that her behavior towards her daughter-in-law has always been based on a mentality that tends to reinforce the hostility. The mother identifies her errors of judgment that have blinded her to an accurate view of her daughter-in-law. That is to say, she has allowed her vision to be influenced by goodness rather than hatred.

\section{Representation of Murdoch's Philosophical Perspectives in her The Flight from the Enchanter and A Severed Head}

Murdoch endeavored to encourage the development of morality throughout her prolific philosophical and literary career. Since literature is a mirror to life, and has a significant role in the formulation of ethical principles, Murdoch utilizes her literary works, particularly the novels, to convey philosophical perspectives. She argues that "the novel, the novel proper that is, is about people's treatment of each other, and so it is about human values" (1999: p.135). As a moral philosopher and thinker who applies her philosophical theories on most of her novels, Murdoch exhibits her appreciation of man's desire for the Good through certain characters of her novels. Likewise, as the protagonist of The Flight from the Enchanter, Mischa Fox is a domineering character who plays the role of a jailer reflected in Plato's theory of Forms via hindering the struggles of those who endeavor to perceive the truth. Mischa's selfishness is analogous to that of the aforementioned mother-in-law.

The majority of characters in The Flight from the Enchanter are victims of power exercised by Mischa. Murdoch is critical of omniscient and omnipotent individuals like Mischa whose constant gaze resembles that of jailers in the London Panopticon. As one of his victims, Rosa remarks "... in the past I always felt that whether I went towards him or away from him, I was only doing his will" (The Flight from the 
Enchanter p. 144). Mischa ruthlessly manipulates in the lives of others to preserve his domination over them. Although Murdoch avoids explicit comments on characters, she intends to indicate that Mischa's inability to love others for the sake of themselves has made a villain out of him. Murdoch intends to depict the impacts of selfishness and indifference to others through her portrayal of Mischa's and his behavior. She asserts in a scholarly article that "love is the perception of individuals, (and) the extremely difficult realization that something other than oneself is real" (Murdoch, 1959: p.51).

Although Murdoch urges human beings to exercise sympathy and love, Mischa's world represents the lack of love and morality. Even if he resorts to love, Mischa utilizes love to trap a compassionate lady like Rosa who turns out to be the emancipator of other prisoners jailed in Mischa's cave. Moreover, as the foil for Mischa, Peter is a sympathetic character advocating love and freedom as the sublime values improving man's moral status. Unlike Mischa who imposes his will over other characters, Peter accepts others as they are. He is the sort of individual praised by Murdoch in her works. Though he lives in a society in which morality is disregarded by the majority of people, Peter is indeed typical of considerate individuals for whom moral and cultural values are significant determinants of social behavior.

Murdoch also reflects her understanding of morality and love in A Severed Head, a novel in which the author explores the possibility of adherence to morality among well-educated and high status individuals. Martin Lynch-Gibbon, the narrator of this novel, is comparable to Peter in The Flight from the Enchanter. Martin's life is ordered by convention and morality. He is an educated individual who has married a decent woman and dwells in a well-ordered house. Martin highly appreciates the values of love and selflessness as redeeming assets leading to dignity. Moreover, Martin's attitude towards religion corresponds to Murdoch's viewpoint presented from the standpoint of a moral philosopher. He refers to his wife, Antonio, as a woman who does not believe in any institutional religion despite being a principled lady. In line with Murdoch's rejection of organized religions and conventional religious values that have resulted in degradation of morality, Martin remarks "Antonia, like me, has no religion; but she achieves what might be called religiosity in relation to certain beliefs" (A Severed Head p.16). Murdoch maintains that human beings should create their own morality through reliance on selflessness, love and art.

Murdoch holds that virtuous consciousness helps the mother overcome her flaws and enables her to attain a loving gaze towards the poor girl. Her ascent to goodness enables her to free herself from what had obstructed her moral vision. Hence, although Murdoch utilizes Plato's theory, she highlights ethics while Plato holds that 
one should rely on the power of mind to be released from the prison of ignorance. Murdoch argues that the achievement of a loving picture of the daughter-in-law represents a moral progress in the mother. She refers to this type of constructive change in attitude as "unselfing". Murdoch holds that "happiness is a matter of one's most ordinary everyday mode of consciousness being busy and lively and unconcerned with self. To be damned is for one's ordinary everyday mode of consciousness to be unremitting agonizing preoccupation with self" (1978: p.180).

Murdoch maintains that value would be "transcendent". She rejected the idea of value, or goodness, being created through human choice. Value, she maintains, has to be discovered. According to Murdoch, value extends beyond the human realm. As human beings, we should discover value and goodness through spiritual and moral development. We should appreciate goodness and endeavor to retain it in our lives through the improvement of morality and the continuous refinement of consciousness in ourselves. Unlike her contemporaries who thought of ethics as modeled on rationality, Murdoch contends that ethics should be modeled on art. "Murdoch connects great art with the good and intimations of the good with love, freedom, and moral improvement" (Bove, p.23). Instead of drawing on the will and intellectuality, Murdoch appreciates artistic capacity and aesthetic perception to be the prerequisites of moral regard for others.

According to Murdoch, the practice of aesthetic perception leads to "ego unselfing", or selflessness associated with virtuous individuals. The mother-in-law was not involved in a rational process of fact-finding. In fact, she does not look for any positive characteristic of the girl that might bring about a change in her attitude towards her. She undertakes, instead, an artistic process of self-creation similar to the job of a sculptor. That is to say, the mother-in-law discards her negative perspective that occluded her vision just in the same way that a sculptor cuts those bits in a piece of stone that prevent the design from showing through. Likewise, human beings both discover and create themselves as moral beings. Hence, Murdoch argues that aesthetic experience has a significant role in our ethical lives to make us better people. Art, then, takes us away from the self towards the appreciation of goodness.

According to Murdoch, egotism is an obstacle to an accurate understanding of others, for selfish people are incapable of loving anybody. She recommends the development of virtuous consciousness through empathy, compassion and selfless love. This is a process that might lead to "aesthetic seeing". Murdoch asserts that a true perception of the moral self needs a link between ethics and aesthetics. That is to say, she advocates the dual process of aesthetic perceptiveness and ego "unselfing" that could result in the decentering of the self and developing a virtuous 
behavior. Murdoch holds that virtue is knowledge of the Good which is indeed aesthetic perception. She argues that we can acquire virtue through aesthetic perception or perceiving the intrinsic beauty and goodness of nature and art that contribute to the perfection of our moral concern for human beings.

Murdoch maintains that aesthetic perception leads to the development of virtue and virtuous consciousness. Moreover, such a perception expands the horizon of our understanding concerning the plights and misfortunes affecting our peers. Our virtuous consciousness, Murdoch maintains, should become the major determinant in the development of our moral regard for our contemporaries. Murdoch's arguments obviously indicate the trace and influence of George Edward Moore (1873-1958), an illustrious British philosopher. Moore had already asserted in his seminal book, Principia Ethica (1903), that the good is identifiable and stands for a non-natural quality of states of affairs. Moore maintained that good is a reality above or imperceptible by the senses:

"A great deal has happened since he wrote, and when we read him again it is startling to see how many of his beliefs are philosophically unstatable now. Moore believed that good was a supersensible reality, that it was a mysterious quality, unpresentable and indefinable, that it was an object of knowledge and (implicitly) that to be able to see it was in some sense to have it. He thought of good upon the analogy of the beautiful and considered goodness to be 'a real constituent of the world", (Murdoch, 1970: p.14-15).

Murdoch is not satisfied with the long-established view concerning the motivation behind virtuous actions which maintains that morality and righteousness are efficient factors leading to either spiritual development or happiness for a virtuous person. Although adherence to moral standards for the sake of perfection is the representative of virtue, Murdoch advocates the idea of virtue for the sake of the happiness of others. Since Murdoch was a nonconformist philosopher and thinker with relatively unorthodox theories that aimed at breaking down certain social norms and values, she argues that human beings should be virtuous not because it is beneficial for themselves but because being morally perfect is intrinsically good.

\section{Conclusion}

Murdoch proposed her seminal philosophical theories in an era when selfcenteredness and the desire to pursue materialistic goals, rather than revering spiritual values, was a discernible characteristic of the majority of Britons. Unlike 
the bulk of people, Murdoch considered happiness not as living well but as the endeavor to take the measures that might result in the happiness of others. The Good, then, is apprehended not through reason but via love and affection. Murdoch asserted that seeking virtue would have nothing to do with discovering the permanent truth of abstract values and norms. She argued that human beings possess certain inherent moral qualities that enable them to reach ethical perfection. Any ethical attempt is, indeed, rooted in these moral dispositions that see virtue as a sublime concept in morality. According to Murdoch, affection, sympathy, benevolence and honesty would contribute to the prevalence of morality, whereas jealousy, malevolence and greed mislead human beings. Moreover, Murdoch referred to love as the sublime virtue that would help us overcome selfishness.

\section{References}

Bove, C. K. (1993). Understanding Iris Murdoch. Columbia: University of South Carolina Press.

Clarke, B. (2010). 'Imagination and Politics in Iris Murdoch's Moral Philosophy', Philosophical Papers, 35 (3), pp. 387-411.

Haines, Simon. (2010). 'Iris Murdoch, the Ethical Turn and Literary Value' in Rowe, A. and Horner, A. (eds.) Iris Murdoch and Morality.

Jordan, J.E.G. (2013). 'Thick Ethical Concepts in the Philosophy and Literature of Iris Murdoch', The Southern Journal of Philosophy, 51 (3), pp. 402-417.

Martin, P. and Rowe, A. (2010). Iris Murdoch: A Literary Life. New York: Palgrave Macmillan.

Milligan, T. (2012). 'Iris Murdoch and the Borders of Analytic Philosophy', Ratio, 25 (2), pp. 164-176.

Moore, G. E. (1903). Principia Ethica. Cambridge: Cambridge University Press.

Murdoch, Iris. (1961). A Severed Head. London: London: Penguin Books.

--. (1999). Sartre: Romantic Rationalist. London: Vintage Books.

--. (1958). The Bell. London: Chatto and Windus.

--. (1956). The Flight from the Enchanter. London: Penguin Books, 1956.

--. (1964). 'The Idea of Perfection', The Yale Review, 53 (3), pp. 342-380.

--. (1978). The Nice and The Good. London: Penguin Books.

--. (1970). The Sovereignty of Good. London: Routledge, 1970.

--. (1959). 'The Sublime and the Good', Chicago Review, 13 (3), pp. 42-55.

Weldhen, M. (2006). 'Ethics, Identity and Culture: Some Implications of the Moral Philosophy of Iris Murdoch', Journal of Moral Education, 15 (2), pp. 119-126. 